\title{
El género Pannaria (Pannariaceae) en la Argentina: NUEVOS REGISTROS Y ACTUALIZACIÓN DEL CONOCIMIENTO
}

\author{
The genus Pannaria (Pannariaceae) in Argentina: NeW Records and \\ UPDATED KNOWLEDGE
}

\author{
Alfredo Passo ${ }^{1 *}$, Raúl Enrique Díaz Dominguez ${ }^{2} \oplus$ y Juan Manuel Rodríguez ${ }^{2}$
}

1. INIBIOMA (Instituto de Investigaciones en Biodiversidad y Medioambiente, CONICETUniversidad Nacional Comahue) Quintral 1250, 8400 Bariloche, Argentina.

2. Centro de Ecología y Recursos Naturales Renovables (Universidad Nacional de Córdoba). IIByT (Instituto de Investigaciones Biológicas y Tecnológicas, CONICETUniversidad Nacional de Córdoba), Córdoba, Argentina.

*alfredo.passo@gmail.com

Citar este artículo PASSO, A., R. E. DIAZ DOMINGUEZ y J. M. RODRIGUEZ. 2020. EI género Pannaria (Pannariaceae) en la Argentina: nuevos registros y actualización del conocimiento. Bol. Soc. Argent. Bot. 55: 339-357.

DOI: https://doi. org/10.31055/1851.2372.v55. n3.25727

\section{SUMMARY}

Background and aims: As part of long-term studies focused on the diversity of lichenized fungi in Argentina, a review of the genus Pannaria in the country is presented. This genus have never been studied in detail in our territory.

M\&M: The morphology, anatomy and chemistry of the species were studied through the review of fresh specimens collected in the field and the study of different herbarium collections, following standardized protocols.

Results: Fifteen species of Pannaria are registered for Argentina, 3 of them for the first time: $P$. conoplea, $P$. malmei, and $P$. tavaresii. A new synonym is proposed $(P$. euphylla $=P$. calophylla). Descriptions, photographs, and actualized information on their distribution and ecology, and a key for their identification are presented.

Conclusions: Most of the mentioned species were found in the Andean-Patagonian forests, with the exception of $P$. conoplea, $P$. malmei and $P$. tavaresii, which were found in central Argentina, in high altitude forests of Polylepis.

\section{KEY WORDS}

New records, Pannariaceae, Patagonia, South America, taxonomy.

\section{RESUMEN}

Introducción \& Objetivos: Como parte de estudios a largo plazo enfocados en la diversidad de hongos liquenizados en la Argentina, se presenta una revisión sobre el género Pannaria para el país. Este género nunca ha sido estudiado en detalle en nuestro territorio.

M\&M: La morfología, anatomía y química de las especies fue estudiada por medio de la revisión de ejemplares frescos recolectados en el campo y el estudio de diferentes colecciones de herbario, siguiendo protocolos estandarizados.

Resultados: Se registraron 15 especies de Pannaria, 3 de ellas por primera vez para la Argentina: $P$. conoplea, $P$. malmei y $P$. tavaresii. Se propone una nueva sinonimia ( $P$. euphylla $=P$. calophylla). Se presentan descripciones, fotografías e información actualizada sobre la distribución y ecología de las especies, y una clave para su identificación.

Conclusiones: La mayoría de las especies mencionadas se encuentran en los bosques andino-patagónicos, con la excepción de $P$. conoplea, $P$. malmei y $P$. tavaresii, que se encontraron en el centro de Argentina, en bosques de altura de Polylepis.

Palabras clave

América del Sur, Pannariaceae, Patagonia, nuevos registros, taxonomía.

\section{INTRODUCCIÓN}

El género Pannaria Del. (Pannariaceae, Ascomycota liquenizados), se caracteriza por tener un talo folioso, con lóbulos profundamente divididos a laciniados o bien, escamoso con escamas sublobuladas y divididas. Como fotobionte principal puede presentar tanto una Cyanobacteria (Nostoc spp.), como una Chlorophyta (Myrmecia spp.), en cuyo caso también presenta cefalodios externos con Nostoc como fotobionte secundario. Sus apotecios 
son de tipo lecanorino con un margen talino bien desarrollado. El disco es típicamente anaranjado a marrón-rojizo con un himenio hemiamiloide (I+ azul) y ascos octosporados sin estructuras internas amiloideas. Las ascosporas son simples y hialinas con una pared lisa o rugosa. Su química se caracteriza por la presencia de $\beta$-orcinol depsidonas como la pannarina o la vicanicina y de difenil éteres como la leprolomina (Elix et al., 1978, 1982; Ekman et al., 2014).

El género cuenta con aproximadamente 80 especies a nivel mundial, distribuidas principalmente en regiones templado-cálidas, aunque también es relativamente diverso en zonas templado frías de ambos hemisferios (Jørgensen, 1994, Ekman et al., 2014). En la Argentina fueron citadas únicamente 5 especies, todas para la Patagonia (Calvelo \& Liberatore, 2002) y con Nostoc como fotobionte principal, teniendo en cuenta que la delimitación antigua (Jørgensen, 1978) del género solo incluía a este grupo. Sin embargo, la circunscripción actual (Jørgensen, 2001), incluye especies con ambos tipos de fotobionte, de manera que el número de especies presentes podría ser mayor. De hecho, en los últimos años, varias especies de Psoroma Michx., un género afín y filogenéticamente relacionado, fueron transferidas a Pannaria, algunas de las cuales habían sido incluidas bajo ese género en el catálogo de líquenes de la Argentina (Jørgensen, 2001, Calvelo \& Liberatore, 2002, Elvebakk \& Galloway, 2003, Passo et al., 2004, Passo \& Calvelo, 2006). Aun considerando la delimitación actual, Pannaria se mantiene, en el país, como un género de zonas templado-frías, con un centro de diversidad en la Patagonia, y no se conocían, hasta la fecha, especies en otras provincias del país. No obstante, existen grupos de líquenes comunes entre los bosques andino-patagónicos y zonas montañosas del centro y norte de Argentina ya que, debido a la altitud, el clima es templado, como Cetrariastrum Sipman, ahora dentro de Hypotrachyna (Vain.) Hale (Calvelo \& Estrabou, 1997) y algunas especies neuropogonoideas de Usnea Dill. ex Adans. (Wirtz et al., 2012), entre otras.

A continuación, se presenta una revisión de las especies de Pannaria presentes en el país. Se incluyen descripciones, fotografías e información actualizada sobre la distribución y ecología de cada una de las especies. Se incluye a su vez una clave dicotómica para su identificación.

\section{Materiales y Métodos}

Se estudiaron colecciones provenientes de diferentes herbarios nacionales e internacionales, entre éstos, BA, BAFC, BCRU, BM, CORD, H, LIL, MSC y S (siglas según Holmgren \& Holmgren, 2001), incluyendo, cuando fue posible, el ejemplar tipo de cada una de las especies y/o sus respectivos sinónimos. A su vez, se estudiaron especímenes coleccionados en los principales parques nacionales del noroeste de la Patagonia (PN Lanín, PN Nahuel Huapi, PN Bosque de Arrayanes y PN Lago Puelo), donde el género muestra su mayor diversidad. También se analizaron colecciones provenientes de los bosques de Polylepis australis de las Sierras Grandes de Córdoba incluyendo el PN Quebrada del Condorito. Debido a que se observó un gran número de muestras, solo se mencionan especímenes seleccionados, que reflejan la distribución en el país de las especies estudiadas.

Para el estudio de los ejemplares se procedió a la observación de la morfología y anatomía de los talos liquénicos, siguiendo la metodología de Passo et al. (2004). Se realizaron cortes histológicos a mano alzada de los apotecios, montados inicialmente en agua (para la medición de las esporas) y luego se agregó una solución de yodo (reactivo de Melzer o lugol), para observar la reacción amiloide del himenio y el detalle del ápice de los ascos.

Para la identificación de las sustancias liquénicas, se realizaron reacciones puntuales de color, utilizando los siguientes reactivos: hidróxido de potasio en solución acuosa al $10 \%(\mathrm{KOH})$, hipoclorito de sodio $(\mathrm{ClHNa})$ al $40 \%(\mathrm{C})$, y p-fenilendiamina (PD), solución saturada en etanol. A su vez se, se realizaron análisis químicos mediante cromatografía de capa fina (TLC, por sus siglas en inglés), utilizando el solvente C (tolueno/ácido acético) siguiendo metodologías estándares (Orange et al., 2010).

\section{Resultados}

Como resultado de la presente revisión florísticotaxonómica, se describen e ilustran 15 especies de Pannaria para Argentina. Tres de ellas se citan por primera vez para el país y se confirma la presencia de otras 2. Se discuten detalles taxonómicos y se aportan datos sobre la distribución geográfica y ecología de cada especie. 


\section{A. Passo et al. - El género Pannaria en la Argentina}

\section{Clave para las especies de Pannaria de Argentina}

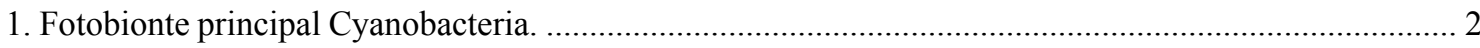

2. Talo escamoso; apotecios negros. ............................................................................... P. hookeri

2'. Talo folioso; apotecios marrón rojizos. ......................................................................................... 3

3. Con soredios o isidios, corteza y médula PD+. ....................................................................... 4

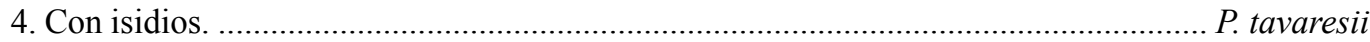

4'. Con soredios, a veces corticados. ......................................................................... P. conoplea

3'. Sin isidios ni soredios, corteza y médula PD-. .............................................................. P. malmei

1'. Fotobionte principal Chlorophyta, cefalodios externos presentes. ..................................................... 5

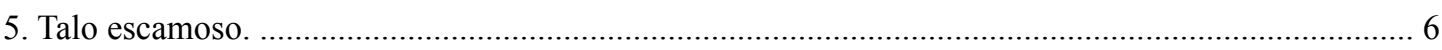

6. Protalo presente, fibroso-bisoide; médula K-. ............................................................................. 7

7. Escamas planas, circulares y glabras. .................................................................. P. byssoidea

7'. Escamas suberectas, alargadas e hirsutas. ............................................................ P. hispidula

6'. Protalo ausente o, si presente, fino y carbonoso; médula $\mathrm{K}+$, amarillo virando a anaranjado (ácido

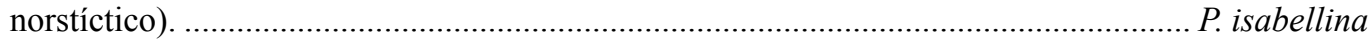

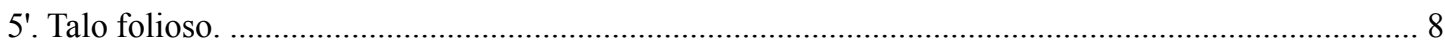

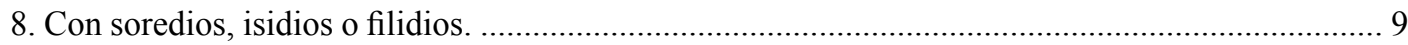

9. Con soredios. …................................................................................................. Parinosa

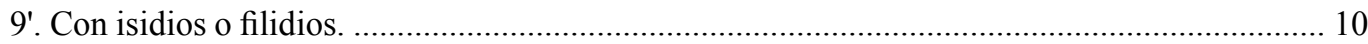

10. Con isidios, esporas con pared lisa. ............................................................ P. pulverulacea

10'. Con filidios, esporas con pared halonada. ................................................. P. athroophylla

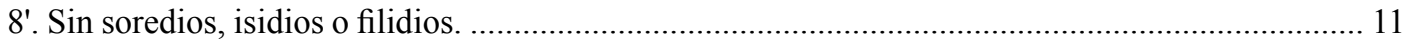

11. Talo adherido al sustrato solo centralmente. .................................................... P. euphylla

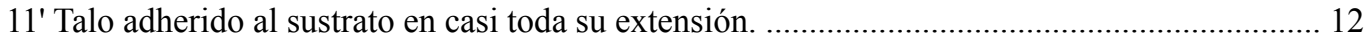

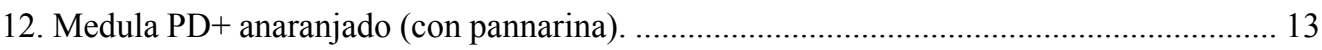

13. Disco del apotecio cóncavo, con anillos concéntricos. ................................... P. contorta

13'. Disco del apotecio plano, sin anillos concéntricos. ......................................... P. pallida

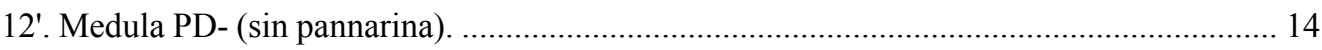

14. Lóbulos angostos, laciniados; esporas con pared lisa. ................................. P. sphinctrina

14'. Lóbulos redondeados, anchos; esporas con pared halonada. .................... P. patagonica

1. Pannaria athroophylla (Stirt.) Elvebakk \& D.J. Galloway, Australasian Lich. 53: 5. 2003. Tipo: New Zealand, on bark of trees, Tinakori Hills, Wellington, J. Buchanan 45 (BM, lectotipo!; isolectotipo WELT). Fig. 1A.

$\equiv$ Psoroma athroophyllum Stirt., Rep. Trans. Glasgow Soc. Field Natural. 1: 21. 1873.

Talo folioso, lobado, orbicular a irregular, de 3 a $5(-10) \mathrm{cm}$ diám., fuertemente adherido al sustrato.
Protalo ausente o con ricinas extendiéndose más allá del talo a modo de protalo. Lóbulos alargados, de 5-12 mm de largo y 1-4 mm de ancho, irregularmente ramificados, contiguos a imbricados en el centro; márgenes enteros a ocasionalmente agrietados, algo engrosados e involutos, filidiados. Filidios erectos, dorsiventrales, digitiformes a ramificados, muy abundantes en el centro del talo. Superficie superior lisa a irregular, agrietada en partes, verde claro cuando húmeda, blanco-crema cuando seca, mate; 

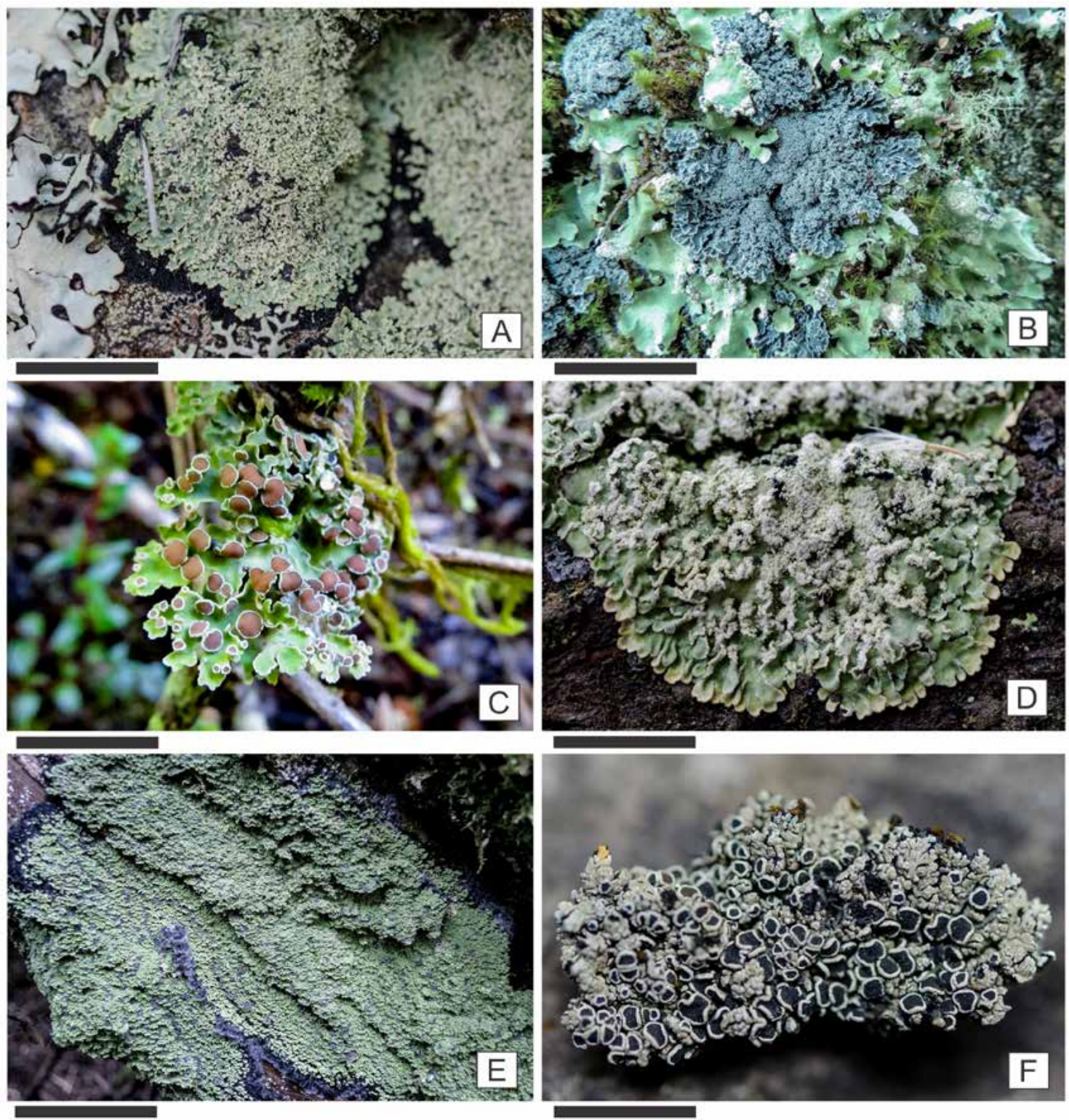

Fig. 1. Aspecto general de: A: Pannaria athroophylla. B: P. conoplea. C: P. euphylla. D: P. farinosa. E: P. hispidula. F: P. hookeri. Escalas: A-D, $F=2 \mathrm{~cm} ; \mathrm{E}=3 \mathrm{~cm}$.

sin tomento. Fotobionte Myrmecia. Superficie inferior blanca, sin corteza, cubierta, hacia el centro, por una densa capa de ricinas negras, escuarrosas, que se proyectan 2 a $3 \mathrm{~mm}$ más allá del talo. Cefalodios gris azulado, globosos a cerebroides, desarrollándose en la superficie inferior y proyectándose entre los lóbulos. Apotecios circulares a irregulares, 1 - 4 mm diám.; disco marrón rojizo, plano, sin fisuras, anillos o pruina; margen finamente crenado a escamoso hasta filidiado. Himenio I+ azul; ascos sin estructura interna amiloidea; ascosporas elipsoides a subglobosas, $18-20 \times 10-12 \mu \mathrm{m}$, exosporio liso, rodeadas por un perisporio irregular halonado, con un apículo largo en cada extremo.

Química: K-, C-, PD-; leprolomina (mayor) y vicanicina (mayor a menor). 


\section{A. Passo et al. - El género Pannaria en la Argentina}

Distribución geográfica. Pannaria athroophylla fue considerada previamente como endémica de Nueva Zelanda (Galloway, 1985, 2007). Esta especie fue incluida en un estudio molecular sobre el género Psoroma (Passo et al., 2008), donde se especifica que el material utilizado proviene de la Argentina, pero aquí se cita y describe por primera vez de manera completa para América del Sur. En la Argentina se encuentra en las provincias de Neuquén, Chubut, Río Negro, Santa Cruz y Tierra del Fuego.

Especímenes seleccionados. ARGENTINA. Prov. Chubut: Depto. Cushamen, Lago Puelo, puesto de Gendarmería Nacional, sobre $A$. chilensis, 4-III-2004, Passo 251 (BRUC 04893). Prov. Neuquén: Depto. Los Lagos, Parque Nacional Lanín, cascada del Río Chachin, sobre Myrceugenia exsucca, 19-III-2004, Passo 180 (BCRU). Prov. Río Negro: Depto. Bariloche, Bariloche, Villa Tacul, lugar expuesto, exp. O, sobre $A$. chilensis, 23-III-2003, Passo 274 (BCRU). Prov. Santa Cruz: Depto. Lago Argentino, Cerro Mayo, sobre tronco de N. pumilio, 1959, James s/n, (BM 762032). Prov. Tierra del Fuego: Depto. Ushuaia, Lapataia, Laguna Verde, sobre rocas, 11-I-1970, Roivainen s/n (H); Sierra Sorondo, the northern slope above Las Cotorras, about 20 km ENE Ushuaia, 8-XI-1940, Santesson 845 (S 47257); Isla de los Estados, Puerto Hoppner, on Nothofagus, 09-XI-1971, Imshaug 53760 (MSC 120162).

Observaciones. Pannaria athroophylla se caracteriza por su talo folioso con abundantes filidios, que surgen en los márgenes, pero comúnmente cubren casi la totalidad del talo. Se diferencia de otras especies con propágulos, como P. farinosa Elvebakk \& J. Fritt-Rasm (sorediada) y $P$. pulverulacea Elvebakk (isidiada), por las esporas rodeadas por un perisporio halonado, con un apículo largo en cada extremo. Típicamente, esta especie no presenta protalo, pero en ocasiones las abundantes ricinas negras se extienden más allá del talo, semejando dicha estructura (Fig.1A). De hecho, anteriormente la especie fue descripta con protalo (Galloway, 1985), pero de acuerdo a nuestro criterio, no sería un protalo verdadero. De acuerdo a la literatura, un protalo está formado por hifas indiferenciadas que, en su crecimiento, van extendiéndose y captando algas para formar el talo liquénico (Barreno \& Pérez-Ortega, 2003). Las ricinas, por el contrario, tienen la función de adherencia al sustrato. Por ese motivo, por más que se extiendan más allá del talo, no forman un verdadero protalo. Un claro por ejemplo de protalo se puede ver en las especies escamosas, como P. byssoidea Passo \& Calvelo, cuyo crecimiento se da por la aparición de nuevas escamas en los márgenes, mientras que, en las especies foliosas, en la cuales el crecimiento es por el alargamiento de los ápices de los lóbulos, no suele haber protalo.

Es una especie típicamente muscícola, especialmente en su distribución más austral, aunque es común encontrarla también sobre cortezas.

2. Pannaria byssoidea Passo \& Calvelo, Bryologist 114: 757. 2011. Tipo: Argentina, Río Negro, Bariloche, Puerto Blest, costa del Río Frías, sobre Nothofagus dombeyi, 6-IV-2006, Passo 274 (holotipo: BCRU 5229; isotipo: H). Fotografía: Passo \& Calvelo, 2011: 758.

Talo escamoso, orbicular, de 3 a $8 \mathrm{~cm}$ diám., fuertemente adherido al sustrato. Protalo presente, conspicuo, notoriamente fibroso-bisoide, marrón oscuro a negro, extendiéndose 3 - 4 mm más allá del talo. Escamas circulares a sublobuladas, de 0,1 a 2 $\mathrm{mm}$ de diám., discretas a contiguas y aglomeradas en el centro. Superficie superior lisa, brillante a cerosa, blanquecina a verde pálido cuando seca, verde claro cuando húmeda, frecuentemente con los bordes más claros, con una finísima capa de pelos sedosos blancos (aumento $20 \mathrm{x}$ ). Fotobionte Myrmecia. Superficie inferior sin corteza, adherida al sustrato, no visible. Cefalodios abundantes, conspicuos, gris azulados cuando húmedos, escamosos cerebroides, de hasta $2 \mathrm{~mm}$ de diám., creciendo entre las escamas. Apotecios abundantes, circulares a irregulares o deformes, de $1 \mathrm{a} 3 \mathrm{~mm}$ diám.; disco anaranjado a marrón oscuro, plano a cóncavo, frecuentemente con depresiones concéntricas o con una escama estéril en el centro; margen grueso, crenado, de 0,1-0,2 mm. Himenio I+ azul; ascos sin estructura interna amiloidea; ascosporas elipsoides a subglobosas, 16,3 - $20 \times 10$ - 12,5 $\mu \mathrm{m}$, exosporio rugoso, de $1-2 \mu \mathrm{m}$.

Química: Médula K-, C-, PD-; leprolomina (mayor). 
Distribución geográfica. Pannaria byssoidea es una especie endémica de América del Sur. En la Argentina se encuentra en las provincias de Neuquén, Río Negro y Tierra del Fuego. Posiblemente se la encuentre también en la provincia de Chubut, aunque no se estudió material de esa zona. En Chile sigue aproximadamente la misma distribución, desde la Región de los Lagos hasta la Región de Magallanes (Passo \& Calvelo, 2011).

Especimenes seleccionados. ARGENTINA. Prov. Neuquén: Depto. Lacar, Lago Queñi, sobre $N$. dombeyi, 19-III-2004, Passo 253 (BCRU). Prov. Río Negro: Depto. Bariloche, Puerto Blest, picada a Laguna los Cántaros, 02-VIII-2002, Passo 84 (BCRU 04908). Prov. Tierra del Fuego: Depto. Ushuaia, Bahía Buen Suceso, on Nothofagus, 14-X1971, Imshaug 50087 (MSC 118725).

Observaciones. Pannaria byssoidea es fácilmente distinguible por su talo escamoso rodeado de un protalo negro fibroso-bisoideo y sus escamas circulares, planas, lisas y algo brillantes. Cuando está húmedo, se destaca en el campo por sus cefalodios gris azulados, visibles a simple vista. En la Patagonia crece en los bosques húmedos, como el bosque lluvioso templado y la selva valdiviana. Hacia el sur, donde los bosques de $N$. pumilio y $N$. betuloides son también húmedos es una especie frecuente. Dentro de estos bosques, se ubica en sitios abiertos y más bien luminosos, aunque parece ser considerablemente tolerante a la sombra.

Esta especie fue citada para Chile como Psoroma implexum Stirt. (Galloway \& Quilhot, 1998), una especie muy similar originaria de Nueva Zelanda. Estudios posteriores determinaron que en realidad era una especie diferente y nueva para la ciencia (Passo \& Calvelo, 2011).

3. Pannaria conoplea (Ach.) Bory, Dict. Class. Hist. Nat. 13: 20. 1818. Tipo: Francia ("Galia"), sin datos de localidad, Persoon (H-ACH 1409, lectotipo fide Jørgensen, 1978: 21). Fig. 1B.

EParmelia conoplea Ach., Lich. Univ.: 467. 1810.

Talo folioso, orbicular a irregular, de 2 a $3 \mathrm{~cm}$ de diám., estrechamente adherido al sustrato. Protalo ausente. Lóbulos cortos, de 1-3 $\mathrm{mm}$ de ancho y 3-5 $\mathrm{mm}$ de largo, profundamente incisos, en su mayoría cóncavos, contiguos a discretos en los ápices; márgenes ligeramente engrosados, enteros o con pequeñas muescas, generalmente más pálido que el resto del talo, sorediada. Soredios granulosos, gris azulado, oscurecidos y parcialmente corticados hacia los ápices (pseudoisidios), desarrollándose a partir del margen decorticado de los lóbulos, a menudo creciendo sobre la lámina, formando una costra densamente arenosa. Superficie superior ligeramente escabrosa, gris plomo a gris azulado cuando húmedo, pálido cremoso cuando seco, a menudo cubierta por pruina, especialmente hacia los márgenes. Fotobionte Nostoc. Superficie inferior blanquecina y glabra en una zona muy estrecha en los márgenes, luego cubierta por una fina capa de ricinas azul oscuro a parduzco. Apotecios desconocidos.

Química: Médula K-, C-, PD+ anaranjado; pannarina (mayor).

Distribución geográfica. Especie muy común en el hemisferio norte, en Europa y América del Norte (Jørgensen, 1978, Jørgensen \& Galloway, 1992). Fue citada para Chile (Galloway et al., 2006). La presente constituye la primera cita para el país. En la Argentina fue encontrada la Provincia de Córdoba, en la región de las Sierras Grandes y en el noreste de la Patagonia, en Río Negro y Chubut.

Especímenes seleccionados. ARGENTINA. Prov. Chubut: Depto. Cuchamen, Lago Puelo, acampe cerca del puesto de Gendarmería, sobre Austrocedrus chilensis, 4-III-2004, Passo 161 (BCRU). Prov. de Córdoba: Depto San Javier. El Hueco, sobre Maytenus boaria, alt. 2869, 18-X2018, Rodríguez - Díaz P514 (BCRU). Depto. Punilla, Los Gigantes, sobre roca, alt. 2261, 06-III2015, Rodríguez 2869 (BCRU). Prov. Río Negro: Depto. Bariloche, Lago Moreno, sobre Populus nigra, 1-III-2006, Passo 280 (BCRU).

Observaciones. Esta especie con Cyanobacteria como fotobionte primario se caracteriza por su talo folioso con soredios, que normalmente cubren la totalidad del talo. Es una especie típicamente corticícola, aunque en este trabajo se la encontró también creciendo sobre roca. En la Patagonia se la ha encontrado en lugares expuestos en bosques xerófilos. Su hallazgo en la provincia de Córdoba posiblemente indique que la especie tiene un patrón de distribución diferente a las especies con algas verdes. 


\section{A. Passo et al. - El género Pannaria en la Argentina}

4. Pannaria contorta (Müll. Arg.) Passo \& Calvelo, Lichenologist 38: 553. 2006. Tipo: Chile, Orange Bay, P. Hyades (G, lectotipo! fide Galloway 1985: 472).

三Psoroma contortum Müll. Arg., Miss Scient. Cape Horn Bot. 5: 160. 1888. Fotografía, Passo \& Calvelo 2006: 552.

Talo folioso, laciniado-lobado, de 3 a $7 \mathrm{~cm}$ de diám., estrechamente adherido al sustrato. Protalo ausente. Lóbulos laciniados, cortos, de 8 - $10 \mathrm{~mm}$ de largo y 3 - $5 \mathrm{~mm}$ de ancho, discretos en los márgenes a más o menos imbricados centralmente. Superficie superior lisa, áspera a finamente verrucosa, verde blanquecina cuando húmeda, verde pálido a gris-verdoso cuando seca. Fotobionte Myrmecia. Superficie inferior blanquecina, cubierta por un fino tomento blanco, tornándose ocráceo hacia los bordes de los lóbulos, o con ricinas negras escuarrosas. Cefalodios de color marrón oscuro a pálido, globosos a cerebriformes, en la cara inferior o proyectándose entre los lóbulos sobre la superficie superior. Apotecios frecuentes, a menudo aglomerados en el centro, circulares a deformes y plegados, 1 - 3 mm diám.; disco anaranjado-marrón, plano a convexo, pruinosos, con anillos concéntricos; margen grueso, crenado, a menudo oscureciendo el disco, concoloro con el talo. Himenio I + azul; ascos $\sin$ estructura apical amiloide; ascosporas globosas a subglobosas $12,5-17$ x 12,5 - $14 \mu \mathrm{m}$, exosporio grueso, finamente rugoso.

Química: Médula K-, C-, PD+ anaranjado; pannarina (mayor).

Distribución geográfica. Pannaria contorta es una especie de distribución austral, conocida para Nueva Zelanda (Galloway, 1985) y América del Sur, donde fue citada previamente para Chile (Müller Argoviensis, 1888, Galloway \& Quilhot, 1998) y para la Argentina (Passo \& Calvelo, 2006). Se la encuentra a lo largo de toda la Patagonia.

Especimenes seleccionados. ARGENTINA. Prov. Neuquén: Depto. Lacar, Lago Lacar, Pucará, sobre rama caída de Nothofagus dombeyi, 2004, Passo 142 (BCRU 04901). Prov. Río Negro: Depto. Bariloche, Lago Nahuel Huapi, Puerto Blest, 7-VII1897, P. Dusén 171 (S 47171). Prov. Santa Cruz: Depto. Lago Argentino, Cerro Mayo, on boles of
Nothofagus dombeyi, near the Cerro Mayo glacier in small wood, 1959, James 2038 (BM 762060). Prov. Tierra del Fuego: Depto. Ushuaia, Ushuaia, 25-XI-1997, Calvelo \& Adler 2037 (BCRU).

Observaciones. Pannaria contorta se caracteriza por su hábito folioso laciniado y por sus apotecios circulares con anillos concéntricos sobre el disco, claramente marcados. Es una especie típicamente corticícola. Habita en lugares más bien luminosos, en bosques abiertos, en claros o bordes de senderos.

5. Pannaria euphylla (Nyl.) Elvebakk \& D.J. Galloway, Australasian Lich. 53: 5. 2003. Tipo: New Zealand, sine loco, sine collectoribus, ex Herb. Churchill Babington (H·NYL 30800). Fig. $1 \mathrm{C}$.

三 Psoroma euphylum Nyl., Syn. Meth. Lich. 2: 21. 1863.

= Pannaria calophylla (Müll. Arg.) Passo \& Calvelo, Lichenologist 38: 550. 2006. Tipo: Chile, E. C. Reed n. 28 (BM ex K; G). Syn. nov.

Talo folioso lobado, más o menos orbicular, de 4 a $8 \mathrm{~cm}$ diám.; adherido al sustrato solo en el centro. Protalo ausente. Lóbulos anchos, 3 - 4 $\mathrm{cm}$ de largo, hasta $2 \mathrm{~cm}$ de ancho, profundamente divididos, cóncavos; márgenes crespos. Superficie superior irregular a rugosa, papilosa en partes; verde claro a blanquecina cuando húmeda, glauco pálido cuando seca, mate; lóbulos jóvenes con pelos blancos hialinos. Fotobionte Myrmecia. Superficie inferior algodonosa, blanca a marrón, con ricinas escuarrosas en el centro. Cefalodios concoloros con el talo cuando secos a gris azulados cuando húmedos, globosos a ligeramente cerebroides, sobre ambas caras. Apotecios circulares a irregulares, 0,5 - $4 \mathrm{~mm}$ diám., principalmente marginales; disco anaranjado a marrón oscuro, plano a cóncavo, ocasionalmente fisurado cuando maduros, pruinoso cuando inmaduros; margen fino, crenado, concoloro con el talo. Himenio I+ azul; ascosporas globosas a subglobosas, $16-18 \times 10-12 \mu \mathrm{m}$; exosporio grueso, rugoso.

Química: Médula K-, C-, PD+ anaranjado; pannarina (mayor), norpannarina (menor); ácido porfirílico ocasionalmente presente.

Distribución geográfica. Pannaria euphylla se encuentra en Nueva Zelanda (Galloway, 2007) y 
en América del Sur, en Argentina y Chile. En la Argentina es una especie extremadamente rara y con una distribución restringida, se la ha encontrado en las Provincias de Rio Negro y Chubut.

Especimenes seleccionados. ARGENTINA. Prov. Chubut: Depto. Futaleufú, Lago Verde, sobre Saxegothaea conspicua, 1941, Kühneman s/n (BA 5462); Lago Menéndez, 1945, Castellanos s/n (LIL 2459); Lago Menéndez, at the end of the SW arm of the lake, on paludidified level ground on S side of the river, Fitzroya cupressoides-Nothofagus dombeyi forest, 1938, Kalela 245 (H s/n). Prov. Río Negro: Depto. Bariloche, Parque Nacional Nahuel Huapi, Lago Nahuel Huapi, Puerto Blest, picada a Puerto Cántaros, costa del Río Cántaros, sobre Saxegothaea conspicua, 2002, Passo 101 (BCRU 04909).

Observaciones. Pannaria euphylla es fácilmente reconocible por su talo libre del sustrato, característica única entre las especies de Pannaria de América del Sur, lo que la asemeja a especies de Pseudocyphellaria Vain. Crece casi exclusivamente sobre ramas o ramitas, y es muy común encontrarla sobre Saxegothaea conspicua o Podocarpus nubigena (Podocarpaceae), forófitos que forman parte del segundo estrato arbóreo en los bosques lluvioso templados de la Patagonia.

Anteriormente, Passo \& Calvelo (2006), analizaron la posible sinonimia entre $P$. euphylla y $P$. calophylla, pero se concluyó que eran especies distintas. Contrariamente, análisis moleculares posteriores demostraron que no existen diferencias en las secuencias de ITS de ambas especies (Passo et al., 2008). Entre las características utilizadas para diferenciarlas se mencionan: la presencia de ácido porfirílico, además de pannarina en $P$. euphylla, y una mayor estratificación en la corteza superior en $P$. calophylla (Passo \& Calvelo, 2006). Sin embargo, el análisis de un mayor número de colecciones de ambas especies, así como el ejemplar tipo de $P$. euphylla (el cual no había sido posible estudiar en el año 2006), permitió determinar que el ác. porfirílico no siempre está presente. El ejemplar tipo fue analizado por HPLC (de acuerdo a las anotaciones junto a la etiqueta), y solo contiene pannarina. Considerando la evidencia molecular, así como los análisis químicos realizados, se propone aquí a $P$. calophylla como un nuevo sinónimo de $P$. euphylla.
6. Pannaria farinosa Elvebakk \& J. Fritt-Rasm., Lichenologist 39: 353. 2007. Tipo: Argentina, Tierra del Fuego, near Viamonte, 21-IV-1948, E.C. Migdalski 2 (FH, holotipo!). Fig. 1D.

三 Psoroma isidiosum C.W. Dodge, Nova Hedwigia 12: 332.1967 (1966).

= Psoroma leprolomum var. roseolum Räs., Ann. Soc. Scient. Arg. 128: 144. 1939.

Tipo: Argentina, Parque Nacional Nahuel Huapi, Lago Moreno, en plantas vivas, 800 m, 27. II. 1936, A. Donat 25 (H, holotipo!).

Talo folioso, lobado, más o menos orbicular a irregularmente radiado, de 5 a $10 \mathrm{~cm}$ diám., flojamente adherido al sustrato en los bordes. Protalo ausente. Lóbulos cortos y muy ramificados, subdicotómicos, de 2 - 3,5 $\mathrm{mm}$ de ancho, 5 - 10 $\mathrm{cm}$ de largo, planos a cóncavos, con los márgenes elevados; márgenes sorediados. Soralios labriformes, originándose en la parte inferior de los lóbulos, en el centro del talo frecuentemente cubriendo casi totalmente los lóbulos; soredios granulares, farinosos. Superficie superior verde claro cuando húmeda, verde-grisácea a blanquecina cuando seca, lisa, mate, ocasionalmente agrietada, con una fina capa de pelos sedosos blanquecinos en los extremos. Fotobionte Myrmecia. Superficie inferior parda, cubierta por ricinas escuarrosas, marrones a negras, que ocasionalmente protruyen más allá del talo. Cefalodios abundantes, concoloros con el talo a más claros o grisáceos cuando húmedos, inicialmente globosos, tornándose cerebroides, sobre la cara inferior, creciendo entre las ricinas, proyectándose entre los márgenes de los lóbulos hacia la superficie superior. Apotecios generalmente ausentes o, cuando presentes, poco abundantes, circulares a deformes, 1 - 1,5 mm diám.; disco marrón rojizo oscuro, plano a irregular por mutua presión, epruinoso, sin fisuras, margen crenado, con o sin soredios. Himenio I+ azul; ascos sin estructura amiloidea interna; ascosporas elipsoides a ovoides, 17,5 - $25 \times 10$ - 2,5 $\mu \mathrm{m}$, exosporio liso, con un apículo redondeado en cada extremo.

Química: Médula K-, C-, PD-; leprolomina (mayor) y vicanicina (menor).

Distribución geográfica. Pannaria farinosa es una especie de distribución austral. Se encuentra en América del Sur, Nueva Zelanda, Australia y Tasmania (Elvebakk et al., 2007). En América del 


\section{A. Passo et al. - El género Pannaria en la Argentina}

Sur se encuentra ampliamente distribuida a ambos lados de la Cordillera de los Andes en la Patagonia, en Argentina y en Chile (Galloway \& Quilhot, 1998; Calvelo \& Liberatore, 2002; como Psoroma leprolomum (Nyl,) Räs. y Ps. isidiosum).

Especímenes seleccionados. ARGENTINA. Prov. Chubut: Depto. Cushamen, Lago Puelo, los Hitos, sobre base de Austrocedrus chilensis, 4-III-2004, Passo 162 (BCRU). Prov. Neuquén: Depto. Lacar, Parque Nacional Lanín, Lago Lacar, Pucará, sobre $N$. dombeyi, 16-III-200, Passo 207 (BCRU). Prov. Río Negro: Depto., Bariloche, Lago Guillelmo, sobre Schinus patagonicus, V-2004, Passo 119 (BCRU 04906). Prov. Santa Cruz: Depto. Lago Argentino, Cerro Mayo, on Berberis, 9-II-1959, James 1861(BM s/n). Prov. Tierra del Fuego: Depto. Ushuaia, Isla de los Estados, Puerto Cook, 26-XI-1967, Kühnemann 1815 (BA 40481); Puerto Hoppner, on Nothofagus, 8-XI-1971, Imshaug 53597 (TUR s/n). Lago Roca, on $\log , 25-\mathrm{X}-1971$, Imshaug 55005 (TUR s/n). Lago Escondido, 9-XII-1969, Roivainen 901 (H $\mathrm{s} / \mathrm{n}$ ); Península Mitre, north part, $N$. betuloides $-N$. antarctica forest, 4-II-1987, Stenroos 2751 (H s/n).

Observaciones. Pannaria farinosa se caracteriza por la presencia soralios labriformes que frecuentemente cubren casi la totalidad del talo. Es muy similar a $P$. pulverulacea, con la cual comparten un mismo hábitat y es común encontrarlas juntas. Se diferencian en que esta última, presenta "pseudoisidios" (es decir soredios corticados, ver más adelante), de mayor tamaño, y por tener lóbulos más angostos, casi laciniados. A su vez, es muy similar a $P$. leproloma, una especie que fue excluida de América del Sur (Elvebakk et al., 2007). La mayoría de los registros de $P$. farinosa de América del Sur, se encuentran bajo ese nombre.

Pannaria farinosa es una especie muy común en los bosques andino-patagónicos. Crece en lugares abiertos y luminosos sobre corteza, tanto en árboles como arbustos, o incluso sobre rocas.

7. Pannaria hispidula (Nyl.) Hue, Bull. Bot. Soc. Fr. 48: 57. 1902. Tipo: Chile, Arique, in alta montana regionae Myrtus lomae, II-1852, W. Lechler Pl. Chil. 854 (H-NYL 30816, lectotipo! fide Jørgensen, 2002; isotipos! en S y en H-Nyl 30815). Fig. 1E.

$\equiv$ Psoroma hispidulum Nyl. Flora 38: 674. 1855.
Talo escamoso, generalmente formando extensos parches de 10 a $50 \mathrm{~cm}$ diám., excepcionalmente mucho mayores, fuertemente adherido al sustrato. Protalo presente, conspicuo, finamente bisoide, algodonoso, negro-grisáceo a blancuzco, de 2-3 $\mathrm{mm}$ de grosor. Escamas subelongadas, de 3 - 4 $\mathrm{mm}$ de largo, más o menos erectas e inclinadas, imbricadas, enteras, incisas, dispersas y discretas a muy aglomeradas, formando densos cojines de hasta $1 \mathrm{~cm}$ de espesor (en sección vertical). Superficie superior lisa, opaca, verde claro, marrón claro en herbario, cubierta por un fino tomento de pelos hialinos, blanquecinos, cubriendo la totalidad del talo. Fotobionte Myrmecia. Superficie inferior blanquecina, cubierta de ricinas. Cefalodios gris azulado, nodulares a escamosos, creciendo entre las escamas o sobre estas, 1 - 2 mm diám., hirsutos, con pelos más densos que sobre las escamas. Apotecios circulares a deformes, $1-3 \mathrm{~mm}$ diám.; marrón oscuro, disco plano a marcadamente convexo, con zonas donde el himenio se desarrolla por sobre partes viejas, deformando el apotecio; margen talino crenado, hirsuto, frecuentemente incompleto, entonces margen propio observable; margen propio fino, ligeramente más claro que el disco. Himenio, I+ azul; ascos sin estructura amiloidea interna; ascosporas elipsoides, 15 - 17,5 × $10 \mu \mathrm{m}$, exosporio irregular a rugoso, con un apículo en uno o ambos extremos.

Química: Médula K-, C-, PD-; sin sustancias detectadas por TLC.

Distribución geográfica. Pannaria hispidula es una especie endémica de América del Sur (Galloway \& Quilhot, 1998, Calvelo \& Liberatore, 2002). En Argentina, fue citada para las provincias de Neuquén, Río Negro y Tierra del Fuego (Calvelo \& Liberatore, 2002). En Chile tendría una distribución similar.

Especimenes seleccionados. ARGENTINA. Prov. Neuquén: Depto. Los Lagos, Laguna Ortíz Basualdo, sobre $N$. dombeyi, formando un talo extenso de casi $6 \mathrm{~m}$ de altura, 7-III-2007, Passo 287 (BCRU). Prov. Río Negro: Depto. Bariloche, Bariloche, Puerto Blest, Lago Frías, sobre $N$. dombeyi, 8-IX-2004, Passo 112 (BCRU 04910); Lago Frías, forming a large patch on trunk of $N$. dombeyi, near the lake, 11-II-1950, Lamb 5996 (H $\mathrm{s} / \mathrm{n} \&$ CANL $\mathrm{s} / \mathrm{n}$ ). 
Observaciones. Pannaria hispidula se caracteriza por su talo escamoso, hirsuto, con escamas suberectas e inclinadas, frecuentemente imbricadas. Se la encuentra generalmente formando extensos parches, algunas de las colecciones realizadas para este trabajo, asi como colecciones de herbario, citan ejemplares de hasta $6 \mathrm{~m}$ de extensión. Es una especie típica de las zonas más húmedas de los bosques subantárticos, aunque no es muy frecuente.

8. Pannaria hookeri (Borrer ex Sm.) Nyl., Mém. Soc. Natn. Sci. Nat. Cherbourg 5: 109. 1858. Tipo: Escocia, Ben Lawers and Meall Greigh, W. Borrer (lectotipo, fide Jørgensen 1978: BM). Fig. 1F.

$\equiv$ Lichen hookeri Borrer ex Sm., in J.E. Smith \& J. Sowerby, Engl. Bot. 32: 2283. 1811.

Talo subcrustoso a escamoso, orbicular a irregular, de 1 a $5 \mathrm{~cm}$ de diám., fuertemente adherido al sustrato. Protalo presente, negro, carbonoso. Escamas planas a convexas, de 0,5 a $1 \mathrm{~mm}$ de diám., discretas en el margen a superpuestas y agrupadas en el centro. Superficie superior gris azulada a parduzca, escabrosa, más o menos estriada longitudinalmente, ligeramente blanquecina, especialmente en los márgenes de talo. Fotobionte Nostoc. Superficie inferior sin corteza, directamente sobre el sustrato. Apotecios circulares a deformes, 0,4 a $1,3 \mathrm{~mm}$ de diám.; disco negro a marrón oscuro, mayormente plano a ocasionalmente convexo; margen entero, crenulado. Himenio I + azul; ascos sin estructuras internas amiloides; ascosporas anchamente elipsoides a ovadas, exosporio liso, $12-16 \times 6-9 \mu \mathrm{m}$.

Química: Médula K-, C-, PD+ anaranjado; pannarina en pequeñas cantidades.

Distribución geográfica. Pannaria hookeri es una especie de distribución bipolar, ampliamente distribuida en el hemisferio norte, en Europa y América del Norte (Jørgensen, 1978, 2000), y con registros dispersos en el hemisferio sur, para Australia (Kantvilas \& Gueidan, 2018), África (Jørgensen, 2007), Antártida (Øvstedal \& LewisSmith, 2001), Nueva Zelanda (Galloway, 2007), y también para la Argentina y Chile (Jørgensen, 1978), aunque dicha cita no fue incluida en el Catálogo de líquenes de la Argentina. Por lo tanto, se corrobora aquí su presencia en el país.
Especímenes seleccionados. ARGENTINA. Prov. Río Negro: Depto. Bariloche, Parque Nacional Nahuel Huapi, Cerro Tronador, en la base del glaciar Ventisquero Negro, sobre morena, I-2009, Garibotti 122 (BCRU). Prov. de Santa Cruz: Depto. Lago Argentino, Estancia Lago Roca, Río Rico, sobre rocas cerca del río, 26-I-1959, James $1140^{a}$ (BM 1104041). El Chaltén, Glaciar Huemul, sobre morena, I-2007, Garibotti 103 (BCRU).

Observaciones. A diferencia de las otras especies incluidas en este trabajo, $P$. hookeri se encuentra en ambientes alto-andinos. Jørgensen (1994, 2000) la incluye en un subgénero aparte, Cryopannaria P.M. Jørg., que se caracteriza por poseer talos escamosocrustosos y encontrarse en ambientes árticos/ antárticos. En Argentina este tipo de ambientes se encuentra pobremente estudiado y es posible que otras especies de este subgénero estén también presentes.

9. Pannaria isabellina (Vain.) Elvebakk \& Bjerke, Lichenologist 37(1): 48. 2005. Tipo: Chile, in regionibus andinis, F.W. Neger 94 (TUR-V 12003, holotipo!). Fig. 2A.

Talo escamoso, desarrollándose irregularmente sobre el sustrato, de 2 a $5 \mathrm{~cm}$ diám. Protalo negro ocasionalmente presente, finamente fibroso. Escamas circulares a sub-lobuladas, hasta $3 \mathrm{~mm}$ de largo, con los bordes ascendentes, imbricadas. Superficie superior lisa, opaca, verde claro cuando húmeda, verde pálido cuando seca. Fotobionte Myrmecia. Superficie inferior blanquecina, lisa, sin ricinas. Cefalodios grisáceos cuando húmedos, concoloros con el talo cuando secos, frecuentes, escamosos, difíciles de distinguir en ejemplares de herbario. Apotecios frecuentes, circulares a ligeramente plegados, 1 - 2 mm diám.; disco marrón rojizo, plano a irregular en la madurez, epruinoso; margen bien definido, crenado. Himenio I+ azul; ascos sin estructura interna amiloidea; ascosporas subglobosas a elipsoides, $15-20 \times 10-12,5$ $\mu \mathrm{m}$, exosporio grueso, $2,5 \mu \mathrm{m}$, rodeadas por un perisporio halonado, con un apículo muy largo en cada extremo, de hasta 7,5 $\mu \mathrm{m}$.

Química: Médula C-, PD-, K+ amarrillo virando al rojo; ácidos norstíctico (mayor) y connorstíctico (menor). 


\section{A. Passo et al. - El género Pannaria en la Argentina}
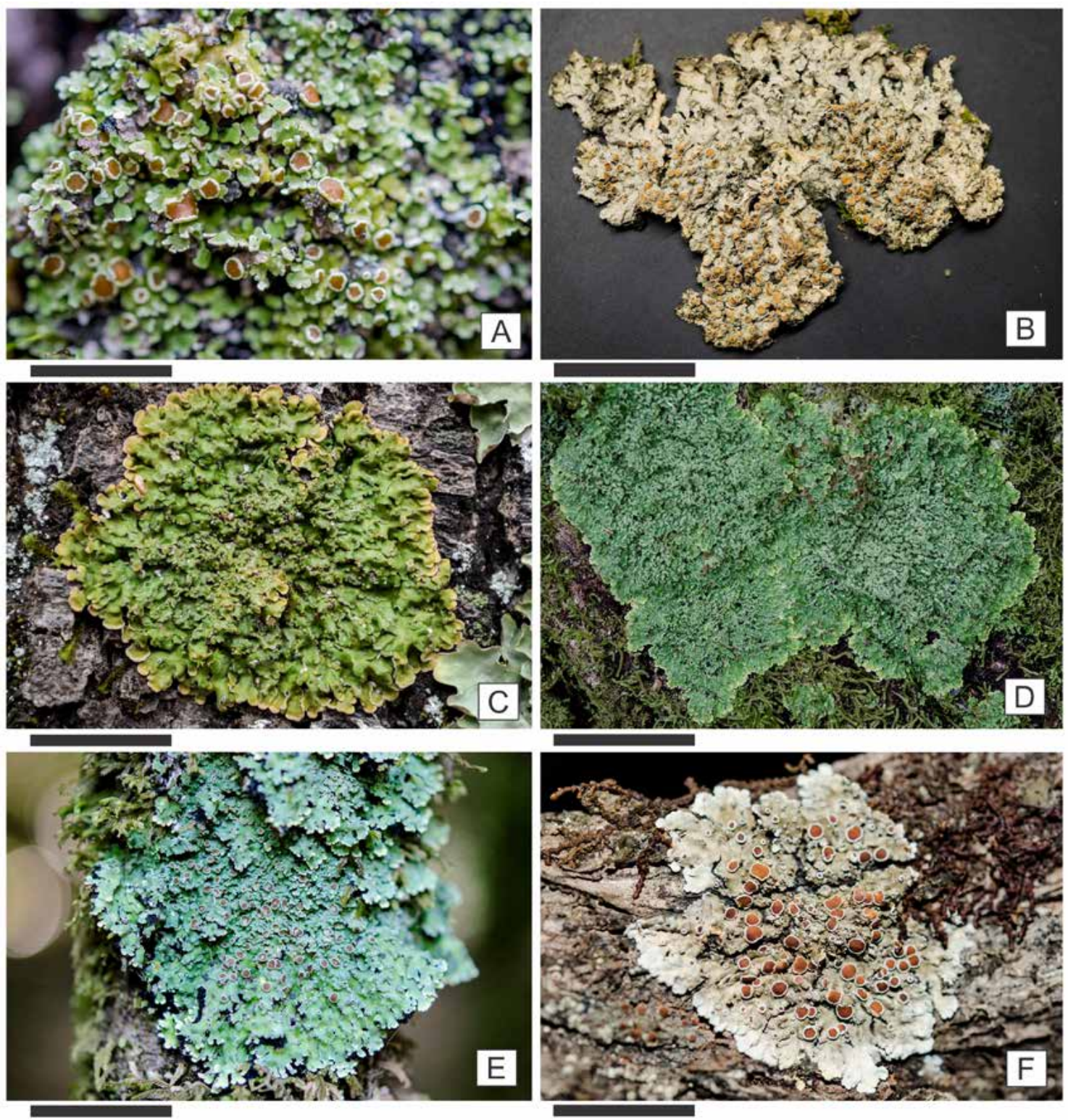

Fig. 2. Aspecto general de: A: Pannaria isabellina. B: P. malmei. C: P. patagonica. D: P. pulverulacea. E: $P$. sphinctrina. F: P. tavaresii. Escalas, A, E, F= $2 \mathrm{~cm} ; \mathrm{B}, \mathrm{C}-\mathrm{D}=4 \mathrm{~cm}$.

Distribución geográfica. Especie endémica del sur de América del Sur (Elvebakk \& Bjerke, 2005). Si bien ésta sería la primera cita formal de la especie para la Argentina, la misma ya había sido incluida justo a las colecciones estudiadas por Passo et al. (2008). En la Argentina se encuentra en las zonas más húmedas del noroeste de la Patagonia, donde es relativamente común.
Especímenes seleccionados. ARGENTINA. Prov. Chubut: Depto. Cuschamen, Lago Puelo, puesto de Gendarmería Nacional, bosque luminoso, sobre N. dombeyi, 4-III-2004, Passo 187 (BCRU). Prov. Neuquén: Depto. Lacar, Lago Queñi, sobre N. dombeyi, 19-III-2004, Passo 139 (BCRU); Lago Lacar, Pucará, sobre N. dombeyi, 17-III2004, Passo 250 (BCRU 04892). Prov. Río Negro: 
Depto. Bariloche, Puerto Blest, inicio de picada a Cántaros, sobre N. dombeyi, 8-IX-2004, Passo 152 (BCRU 039985).

Observaciones. Pannaria isabellina se caracteriza por su hábito escamoso, con escamas subelongadas, bastante desarrolladas y por sus cefalodios escamosos, similares a las escamas en forma y tamaño, pero muy conspicuos al humedecerse. Otra característica única de esta especie es la presencia de ácido norstíctico en la médula $(\mathrm{K}+)$. Las esporas son muy características, elipsoides, con un perisporio halonado con un apículo muy largo en cada extremo, aunque este tipo de esporas aparece también en $P$. patagonica (Malme) Elvebakk \& Galloway y $P$. athroophylla, y en otras especies del género de Nueva Zelanda. Es una especie relativamente común de los bosques lluviosos templados. Crece en lugares más bien luminosos, generalmente sobre ramas o sobre troncos, en bordes de caminos o senderos, aunque también se puede encontrar en áreas menos luminosas.

10. Pannaria malmei C.W. Dodge, Ann. Mo. Bot. Gard. 20: 441, 1933. Tipo: Brasil, Río Grande de Sul, Cascata de Pelotas, G. Malme 801 (S, holotipo). Fig. 2B.

Talo folioso, orbicular, hasta $8 \mathrm{~mm}$ de diámetro, más o menos flojamente adherido al sustrato. Protalo ausente. Lóbulos alargados y redondeados, 4-8 $\mathrm{mm}$ de largo, 4-5 $\mathrm{mm}$ de ancho, planos a ligeramente cóncavos, irregularmente ramificados, con los extremos apenas libres del sustrato, márgenes enteros. Superficie superior lisa, mate, gris a parda cuando seca, gris azulado cuando húmeda, a veces pruinosa en los extremos.

Fotobionte Nostoc. Superficie inferior parda, cubierta por una capa de ricinas negro-azuladas, a veces extendiéndose más allá del talo a modo de protalo. Apotecios abundantes, especialmente en el centro, circulares, de hasta $2 \mathrm{~mm}$; disco marrón anaranjado, plano; margen fino, crenado. Himenio I+ azul, ascos sin estructura amiloidea interna; ascosporas elipsoides, 10 - $15 \times 9-9,5 \mu \mathrm{m}$, exosporio rugoso - verrucoso.

Química: C-, K-, PD-, sin sustancias detectadas.

Distribución geográfica. Pannaria malmei es una especie subtropical, fue citada para Brasil, Ecuador y Venezuela (Jørgensen \& Arvidsson,
2004; Jørgensen \& Sipman, 2004). La presente constituye la primera cita para nuestro país. Fue encontrada en la provincia de Córdoba, en bosques bien conservados de Polylepis australis y parecería tener un patrón de distribución diferente al de las especies patagónicas, todavía poco estudiado.

Especímenes seleccionados. ARGENTINA. Prov. Córdoba: Depto. San Javier, El Hueco, sobre roca y musgos, alt. $1900 \mathrm{msnm}, 18-\mathrm{X}-2018$, Rodríguez \& Díaz (BCRU). El Hueco, sobre Maytenus boaria, alt. 1900 msnm, 18-X-2018, Rodríguez \& Díaz (BCRU).

Observaciones. Esta especie es muy similar a $P$. rubiginosa y $P$. rubiginella, dos especies de las que se distinguen principalmente por la fuerte reacción $\mathrm{PD}+$ anaranjado, que revela la presencia de pannarina en su médula y corteza, mientras que $P$. malmei es PD-. Sin embargo, se menciona que $P$. rubiginella puede ser PD- en ocasiones. En tal caso se diferencian en el grado de desarrollo del talo, siendo P. rubiginella de menor tamaño y subescamoso en partes, mientras que en $P$. malmei es más folioso y de mayor tamaño. Tal como se menciona en la introducción, la especie $P$. rubiginosa fue mencionada en el catálogo de líquenes de la Argentina, para las Islas Malvinas (Calvelo \& Liberatore, 2002), pero en base a una cita muy vieja (Hooker \& Taylor, 1854), y la misma fue excluida recientemente de la lista de especies para dicho lugar (Fryday et al., 2020). Se descarta entonces su presencia en el país así como la posibilidad de que dicha mención pudiera en realidad haberse tratado de $P$. malmei.

11. Pannaria pallida (Nyl.) Hue, Bull. Soc. Bot. France 48: 56. 1902. Tipo: Fretum Magellanicum (Chile?, Strait of Magallanes), "supra ligna putrescentia corticesque", sin fecha, Le GuillouLechler (ex Mus. Paris, H-NYL 30827, lectotipo! fide Jørgensen, 2002). Fotografía, Passo et al., 2004: 359

= Psoroma pallidum Nyl., Annal. Scienc. Nat. Bot. Ser. 4: 12. 1859.

=Psoroma pulchrum Malme, Ark. Bot. 20 A (3): 12. 1925.

Tipo: Fuegia (Argentina), Ushuaia, "in truncis Fagi antarcticae”, 8-1-1896, Dúsen 257 (S, L5121 holotipo!). 


\section{A. Passo et al. - El género Pannaria en la Argentina}

Talo folioso, orbicular, de 6 a $10 \mathrm{~cm}$ diám., fuertemente adherido al sustrato en el centro, más o menos libre en los bordes. Protalo ausente. Lóbulos laciniados, radiados, discretos a más o menos imbricados al desarrollarse, ramificado subdicotómicamente, de 6 - $25 \mathrm{~mm}$ de largo y $2-5 \mathrm{~mm}$ de ancho, extremos de los lóbulos generalmente crespos; márgenes irregulares, engrosados, ocasionalmente con pequeños lóbulos secundarios en partes viejas. Superficie superior notablemente irregular, rugosa, pruinosa a finamente tomentosa en partes jóvenes, pelos blancos; verde claro cuando húmeda, blanquecina a glauca cuando seca. Fotobionte Myrmecia. Superficie inferior blanca en los márgenes, marrón claro a oscuro hacia el centro, sin corteza inferior, algodonosa, tomentosa; con ricinas, cortas, hasta $2 \mathrm{~mm}$, simples a escuarrosas, marrones a ocasionalmente negras y extendiéndose más allá del talo en forma de protalo. Cefalodios marrón claro a blanquecinos cuando secos, gris azulados cuando húmedos, globosos a cerebrifomes al desarrollarse, presentes solo en la cara inferior, raramente proyectándose sobre los márgenes, creciendo entre las ricinas o tomento. Apotecios numerosos, aglomerados, 0,5 - $4 \mathrm{~mm}$ de diám., laminares a raramente marginales, circulares; disco rojo a marrón, plano a irregular, densamente pruinoso cuando inmaduros, azul-blanquecino; margen concoloro con el talo, crenado. Himenio I+ azul; ascos sin estructura amiloidea interna; ascosporas globosas a sub-globosas, 11 - 18 x 11$15 \mu \mathrm{m}$, exosporio grueso, $2 \mu \mathrm{m}$, verrucoso.

Química: Médula K-, C-, PD+ anaranjado; pannarina (mayor) y norpannarina (menor).

Distribución geográfica. Pannaria pallida es una especie de distribución austral (Galloway, 1985). Presente en Nueva Zelanda (Galloway, 2007), Australia (Jørgensen \& Galloway, 1992) y América del Sur (Galloway \& Quilhot, 1998, Passo et al., 2004). En la Argentina es una especie muy común, que se encuentra a lo largo de toda la Patagonia andina (Argentina y Chile), muy frecuente en los bosques húmedos de $N$. dombeyi (Passo et al., 2004).

Especimenes seleccionados. ARGENTINA. Prov. Chubut: Depto. Cushamen, Lago Puelo, cerca del puesto de Gendarmería Nacional, sobre N. dombeyi, 3-III-2004, Passo 155 (BCRU). Prov.
Neuquén: Depto. Lacar Lago Lacar, Pucará, sobre N. obliqua, 17-III-2004, Passo 148 (BCRU). Prov. Río Negro: Depto. Bariloche, Cerro Tronador, Ventisquero Negro, sobre tronco de N. pumilio, 11-XII-2001, Passo 05 (BCRU). Prov. Tierra del Fuego: Depto. Ushuaia, Isla de los Estados, Bahía Capitán Canepa, 3-XI-1971, Imshaug 52970 (MSC 116213). Canal de Beagle, Lapataia, on the ground on a deforested hillside, 21-II-1940, Santesson s/n (S 47183). South-West Patagonia, Lago Frío, on dying Nothofagus, on west of lake, alt ca. $100 \mathrm{ft}$, 24-I-1959, James 1246 (BM 762051).

Observaciones. Pannaria pallida se caracteriza por su talo radiado, laciniado, de superficie rugosa y los apotecios planos y pruinosos. Es una especie típicamente corticícola, creciendo sobre troncos de Nothofagus dombeyi, N. pumilio, entre otras especies. Habita en lugares más bien luminosos, en bosques abiertos o bordes de senderos.

12. Pannaria patagonica (Malme) Elvebakk \& Galloway, Australasian Lich. 53: 7 2003. Tipo: Chile, Tierra del Fuego, Punta Arenas, in cortice arborum, 21-XI-1893, P. Dusén (H, lectotipo! fide Elvebakk \& Galloway, 2003, S sintipo!). Fig. 2C.

$\equiv$ Psoroma patagonicum Malme, Ark. Bot. 20A (3): 13.1925.

Talo folioso, más o menos orbicular, de 5 a $10 \mathrm{~cm}$ diám, más o menos flojamente adherido al sustrato. Protalo ausente. Lóbulos anchos, 6-20 $\mathrm{mm}$ de largo, 3-8 $\mathrm{mm}$ de ancho, irregularmente ramificados, extremos redondeados y ensanchados, levemente cóncavos, con los bordes más o menos crespos, contiguos a imbricados en el centro, con lóbulos secundarios semejantes a escamas creciendo sobre el talo (en talos muy desarrollados). Superficie superior lisa, mate a brillante, blanquecina a parda cuando seca, verde oscuro cuando húmeda, con una finísima capa de pelos blanquecinos en partes jóvenes o en los extremos del talo. Fotobionte Myrmecia. Superficie inferior blanca a marrón, con ricinas simples, cortas, ennegrecidas en los márgenes, ocasionalmente extendiéndose más allá del talo. Cefalodios gris azulado cuando húmedos a concoloros con el talo cuando secos, globosos a cerebroides, originándose en la superficie inferior, entre las ricinas, emergiendo entre los lóbulos y extendiéndose sobre la superficie 
superior. Apotecios circulares a algo deformes, 2 - $3 \mathrm{~mm}$ diám.; disco anaranjado-rojizo a marrón cuando secos, ligeramente pruinosos en apotecios jóvenes; margen grueso y prominente, crenado, oscureciendo el disco cuando inmaduros. Himenio, I+ azul; ascos sin estructura amiloidea interna; ascosporas subglobosas a elipsoides, 12,5 - 17,5 x $10 \mu \mathrm{m}$, perisporio halonado, con un apículo largo en cada extremo.

Química: Médula K-, C-, PD-; vicanicina (mayor).

Distribución geográfica. Pannaria patagonica fue citada para Chile (Malme, 1926, Galloway \& Quilhot, 1998), Nueva Zelanda (Elvebakk \& Galloway, 2003, Galloway, 2007) y para la Argentina (Calvelo, 1992). Es una especie relativamente frecuente, que se encuentra en casi toda la Patagonia.

Especimenes seleccionados. ARGENTINA. Prov. Neuquén: Depto. Huiliches, Lago Tromen, 2-I-1938, Kalela 196 b (H s/n). Depto. Los Lagos, Península Quetrihue, Río Hua Huán, sobre $A$. chilenis, 9-II-2005, Passo 224 (BCRU). Prov. Santa Cruz: Depto. Lago Argentino, Lago Frías, cerca de Lago Argentino, 25-I-1965, James 5050 (BM 762089). Prov. Río Negro: Depto. Bariloche, Bariloche, Llao Llao, picada al lago Moreno, sobre N. dombeyi, 01-IV-2002, Passo 064 (BCRU). Prov. Tierra del Fuego: Depto. Ushuaia, Lago Fagnano, on Nothofagus, 21-XI1971, Imshaug 54441 (TUR s/n y BCRU 3296); Lago Fagnano, cabecera del Lago at the eastern end of the Lake, on a $N$. pumilio trunk in a $N$. pumilio forest, 27-III-1940, Santesson 1604 (S 47173).

Observaciones. Pannaria patagonica se caracteriza por su talo folioso lobado, con lóbulos anchos, redondeados, de superficie superior lisa y algo brillante, y por sus esporas halonadas, con un apículo largo en cada extremo que son también características. Ocasionalmente presenta lobulillos secundarios en partes viejas centrales, estas podrían interpretarse como filidios, pero no se ha observado que actúen como propágulos. Se trata de una especie típicamente corticícola, principalmente crece sobre troncos de Austrocedrus chilensis, $N$. dombeyi y $N$. pumilio.
13. Pannaria pulverulacea Elvebakk, Lichenologist 45: 13. 2013. Tipo: New Zealand, South Island, Marlborough, Clarence Ecological Region, Manakau Ecological District, Fyffe-Palmer Scenic Reserve, 42200 S, 173380 E, 330 m, on bark of Fuchsia excorticata in regenerating forest, 29-X-1993, A. E. Wright 12269 (AK 215380). Fig. 2D.

Talo folioso, más o menos circular, de hasta $10 \mathrm{~cm}$ de diám., fuertemente adherido al sustrato. Protalo ausente. Lóbulos alargados, laciniados, ramificados subdicotómicamente, algo imbricados en el centro, con los extremos a veces elevados; márgenes engrosados, con pequeños pseudoisidios (soredios corticados) globosos sobre los márgenes. Superficie superior lisa, algo brillante, gris blanquecino cuando seca, verde claro cuando húmedas, frecuentemente agrietada. Fotobionte Myrmecia. Superficie inferior blanquecina, con ricinas blancas. Cefalodios del mismo color del talo a gris azulados cuando húmedos, globosos a cerebroides, sobre la cara inferior, entre las ricinas, a veces desarrollándose hacia la cara superior entre los lóbulos. Apotecios poco frecuentes, circulares, de 1 a $3 \mathrm{~mm}$ de diám., disco marrón rojizo, plano a cóncavo, con depresiones; margen fino, crenado, a veces pseudo-isidiados. Himenio I+ azul, ascos sin estructura amiloidea interna; ascosporas elipsoides, 15 - 17,5 x 8 - $10 \mu \mathrm{m}$, exosporio finamente rugoso.

Química: Médula K-, C-, PD-; con vicanicina (mayor).

Distribución geográfica. Especie de distribución austral, presente en Australia, Nueva Zelanda y América del Sur (Elvebakk, 2013). En Argentina se la encontró en toda la Patagonia.

Especimenes seleccionados. ARGENTINA. Prov. Chubut: Dpto. Cushamen, Lago Puelo, camino a Los Hitos, cerca del puesto de Gendarmería Nacional, bosque de N. dombeyi, 3-III-2004, Passo 167 (BCRU). Prov. Río Negro: Depto. Bariloche, Puerto Blest, camino a Puerto Alegre, 8-IX-2004, Passo s/n (BCRU). Prov. Neuquén, Depto. Los Lagos, P.N. Nahuel Huapi, Lago Ortíz Basualdo, bosque mixto de $N$. dombeyi-N. pumilio - Saxegothaea conspicua, 6-III-2007, Passo \& Anduaga s/n. (BCRU). Prov. de Tierra Fuego: Depto. Ushuaia, Península Mitre, north part, $N$. betuloides - N. antarctica forest, alt. $100 \mathrm{~m}$, 4-II1978, Stenroos $2751(\mathrm{H})$. 


\section{A. Passo et al. - El género Pannaria en la Argentina}

Observaciones. Pannaria pulverulacea fue descripta recientemente (Elvebakk, 2013), es una especie bastante común en la Argentina, donde se la encuentra en los bosques andino patagónicos, creciendo sobre la corteza de varios árboles. Se la puede confundir con $P$. farinosa, especie con soredios bien definidos, lo que la distingue de $P$. pulverulacea, que posee pseudoisidios. Este término, utilizado en su descripción original, se refiere a estructuras que se originan de la misma forma que un soredio labriforme, sobre el margen, exponiendo la médula, pero desarrollan una corteza que rodea toda su circunferencia. De hecho, a simple vista o con lupa de mano, es muy difícil diferenciarlos de un soredio, pero bajo microscopio se observa claramente la presencia de corteza, de ahí su denominación como pseudoisidio.

14. Pannaria sphinctrina (Mont.) Tuck., Gener. Lich.: 43. 1872. Tipo: Chile, Juan Fernandez, C. Bertero 1630 (PC, lectotipo!).

$\equiv$ Parmelia sphinctrina Mont., Ann. Sci. Nat. Bot. Ser. 2, 4: 90. 1835. Fig. 2E.

Talo folioso, orbicular, de 3 a $10 \mathrm{~cm}$ diám, fuertemente adherido al sustrato. Protalo ausente. Lóbulos más o menos laciniados, 1,5-2 cm de largo, 1 - 2 mm de ancho, irregular a sub-dicotómicamente ramificados, más o menos discretos y radiando en los márgenes del talo, aglomerados, coalescentes en el centro, planos a ligeramente cóncavos; márgenes engrosados, elevados, crespos, enteros, en talos muy desarrollados secundariamente lobulados o escamosos en el centro. Superficie superior lisa, mate a ligeramente brillante, verde brillante cuando húmeda, verde claro a blanquecina cuando seca. Fotobionte Myrmecia. Superficie inferior marrón a blanco-amarillento, con ricinas cortas, marrones en el centro, ennegrecidas en los bordes del talo. Cefalodios concoloros con el talo cuando secos a grisáceos cuando húmedos, globosos a cerebroides, de hasta $1,5 \mathrm{~mm}$ diám., laminares, originándose en la cara superior, ocasionalmente también en la cara inferior. Apotecios circulares a deformes y plegados, de hasta $3 \mathrm{~mm}$ diám., sésiles a subsésiles; disco anaranjado claro a marrón rojizo, plano a frecuentemente cóncavo, con depresiones irregulares y escamas creciendo sobre el disco; margen finamente crenado. Himenio $\mathrm{I}+$ azul; ascos sin estructura amiloidea interna; ascosporas elipsoides $15-17,5 \times 8-10 \mu \mathrm{m}$, exosporio finamente rugoso.

Química: Médula C-, K-, PD-; vicanicina (mayor).

Distribución geográfica. Pannaria sphinctrina es una especie de distribución austral (Galloway, 1985). Se encuentra en América del Sur, en Argentina y Chile (Lamb, 1958, Galloway \& Quilhot, 1998, Calvelo \& Liberatore, 2002), en Australia y Nueva Zelanda (Galloway, 1985, Jørgensen \& Galloway, 1992). En Argentina había sido citada para las provincias de Río Negro, Chubut y Tierra del Fuego (Cavelo \& Liberatore, 2002). Se amplía aquí su distribución a las provincias de Neuquén y Santa Cruz.

Especimenes seleccionados. ARGENTINA. Prov. Chubut: Depto. Futaleufú, Río Navarro, 21-XII-1941, Kühnemann 5476 (BA s/n). Prov. Neuquén: Depto. Los Lagos, P.N. Nahuel Huapi, Lago Ortiz Basualdo, picada hacia el lago, $980 \mathrm{~m}$, sobre Saxegothaea conspicua, 6-III-2007, Passo $\&$ Anduaga s/n (BCRU). Prov. Río Negro: Depto. Bariloche, P.N. Nahuel Huapi, Puerto Blest, camino a Lago Frías, junto al río frías, cerca de "el abuelo", sobre rama caída de N. dombeyi, 6-IV-2006, Passo s/n (BCRUB). Prov. Santa Cruz: Depto. Lago Argentino, Cerro Mayo, on aged Nothofagus, near glacier, 3-II-1959, James 1742 (BM s/n). Prov. Tierra del Fuego: Depto. Ushuaia, Isla de los Estados, Puerto Vancouver, on Nothofagus, 28-X1971, Imshaug 52129 (MSC 118732).

Observaciones. Pannaria sphinctrina se caracteriza por su talo folioso-laciniado y por sus apotecios frecuentemente plegados y deformes. Es muy similar a $P$. pulverulacea, de la cual se diferencia por la presencia de isidios. Pannaria sphinctrina, junto con $P$. pallida, son de las especies de Pannaria de fotobionte verde más comunes en los bosques andino-patagónicos. Crece generalmente sobre corteza en el tronco principal de varias especies de árboles, aunque suele encontrarse también sobre pequeñas ramas y sobre arbustos. En áreas muy húmedas también puede encontrarse sobre rocas o troncos caídos, entre briofitas.

15. Pannaria tavaresii P.M. Jørg., Op. Bot.: 68. 1978. Tipo: USA, Larimer Co., Loveland Heights, 1953, E. Dhahl (O, holotipo). Fig. 2F. 
Talo folioso, orbicular, arrosetado, $1 \mathrm{a} 5 \mathrm{~cm}$ de diámetro, bien adherido al sustrato, a veces con los extremos más libres. Protalo ausente. Lóbulos cortos, angostos, redondeados, 4 a $10 \mathrm{~mm}$ de largo, por 2 a $6 \mathrm{~mm}$ de ancho, irregularmente ramificados, con los márgenes elevados, radiando en los extremos, más o menos contiguos en el centro. Superficie superior lisa, áspera a notablemente escábrida, en ocasiones pruinosa, gris azulada a blanquecina, especialmente en los márgenes, a blanco parduzca en partes viejas; isidiada. Isidios inicialmente granulares, luego digitiformes, laminares y marginales, blanquecinos, a veces con ápice oscurecido. Fotobionte Nostoc. Superficie inferior parda, cubierta de una densa capa de ricinas negro azuladas, a veces extendiéndose más allá del talo a manera de protalo. Apotecios comunes, circulares, de hasta $2 \mathrm{~mm}$ de diám., disco plano, rojo-marrón a marrón claro, ocasionalmente pruinoso cuando inmaduros, margen fino, crenado a isidiado. Himenio I + azul, ascos sin estructuras internas amiloides; ascosporas elipsoides, $15-20 \mathrm{x}$ 9 - $10 \mu \mathrm{m}$, exosporio rugoso.

Química: C-, K-, KC-, $\mathrm{PD}+$ anaranjado; pannarina (mayor).

Distribución geográfica. Especie bastante común en regiones templadas del hemisferio norte, en Europa y América del Norte (Jørgensen, 2000b). También fue citada para el norte del América del Sur, en Ecuador (Jørgensen \& Arvidsson, 2004), y Chile (Galloway et al., 2006). Esta especie también fue incluida dentro del material estudiado por Passo et al. (2008), pero se la describe y cita formalmente aquí para la Argentina.

Especimenes seleccionados. ARGENTINA. Prov. Chubut: Depto. Cushamen, Lago Puelo, cerca del puesto de Gendarmería Nacional, sobre rama de Austrocedrus chilensis, 4-III-2004, Passo 122 (BCRU). Prov. Río Negro: Depto. Bariloche, Bariloche, Villa Tacúl, sobre Austrocedrus chilensis, 23-III-2003, Passo 138 (BCRU).

Observaciones. Pannaria tavaresii es una especie fácil de identificar por su talo blanquecino, gris azulado cuando húmedo $\mathrm{y}$ sus isidios digitiformes que son muy característicos. Si bien fue citada para Chile por el autor de dicha especie (Galloway et al., 2006), encontramos en el material de Argentina ciertas diferencias con las descripciones de Europa o América del Norte, como ser un tamaño menor en las esporas y el grado de desarrollo de los isidios, citados por otros autores como "coraloides" (Jørgensen, 2000b). Por este motivo, no se descarta que el material de América del Sur sea una especie diferente. Sin embargo, serían necesarios estudios moleculares para confirmarlo.

\section{Discusión y Conclusiones}

De 5 especies de Pannaria mencionadas anteriormente en el Catálogo de líquenes de Argentina (Calvelo \& Liberatore, 2002), con el aporte del presente trabajo, se eleva a 15 el número de especies presentes en la Argentina. Cabe destacar que, sin embargo, ninguna de esas 5 especies se incluye aquí, debido a que se encuentran actualmente incluidas en otros géneros: P. leucophaea, actualmente en Vahliella Jørgensen [Vahliellaceae; Wedin et al. (2011)], P. fuegiensis Zahlbr., ahora en Psorophorus Elvebakk \& S.G. Hong (Elvebakk et al., 2010), P. angustata (Pers.) Zahlbr., bajo Pannoparmelia (Müll. Arg.) Darb. y $P$. dichroa Cromb., actualmente en Psoroma (Ekman et al., 2014). Debido a que no fue posible rastrear las colecciones utilizadas por Zahlbruckner para citar a la especie $P$. rubiginosa para las Islas Malvinas (Hooker \& Taylor 1844; Zahlbruckner, 1917), no se pudo corroborar la presencia de esta especie. De todas maneras, ésta fue excluida recientemente de la lista de especies de Islas Malvinas. Por estos motivos, y considerando que la misma no fue encontrada en los muestreos realizados, ni en las colecciones de herbario revisadas, no fue incluida en el presente trabajo. Por otro lado, cabe destacar que la mayor parte de las 15 especies estudiadas, habían sido citadas previamente para el país bajo Psoroma, género donde fueron originalmente descriptas. Nueve de las 15 especies que se incluyen de hecho fueron descriptas originalmente en base a material recolectado en nuestro país o en Chile. Las restantes especies fueron descriptas originalmente para el hemisferio norte o para Nueva Zelanda una de ellas.

Es importante destacar que más allá de las novedades florísticas que aquí se reportan, el presente trabajo constituye un considerable aporte al conocimiento del género en la región, siendo que muchas de las especies que se incluyen eran casi 


\section{A. Passo et al. - El género Pannaria en la Argentina}

desconocidas. En este sentido, el presente estudio significa un redescubrimiento de algunas de ellas y la primera descripción disponible posterior a la diagnosis original en latín.

La mayoría de las especies estudiadas están asociadas a una Chlorophyta como principal fotobionte, siendo solo 4 las que presentan una Cyanobacteria como fotobionte primario. Esto coincide con lo observado en otros países del hemisferio sur, como Nueva Zelanda (Galloway, 2007). Resulta evidente que las especies con algas verdes poseen una distribución austral, considerando que no existen especies de Pannaria con algas verdes para el hemisferio norte (Jørgensen, 2000b). Esto se refleja en la distribución del género en nuestro país, donde las especies con algas verdes se restringen a la región patagónica. A su vez, las especies foliosas con algas verdes, todas se encuentran también en Nueva Zelanda y/o Australia (Galloway, 2007). Esto representa una nueva evidencia de la estrecha relación que existe entre la flora subantártica de la Patagonia y la de Australasia (Galloway, 2008).

De las 15 especies encontradas, se destaca que las únicas 3 que poseen un talo escamoso y algas verdes, $P$. byssoides, $P$. isabellina y $P$. hispidula, son endémicas del sur de América del Sur. Ekman et al. (2014) encontraron en base a estudios moleculares, que estas especies podrían no pertenecer a Pannaria, sin embargo, por falta de soporte las mismas fueron mantenidas dentro del género. Es posible que, con la inclusión de otras especies con esta misma combinación de caracteres, como P. implexa (Stir.) Passo, Calvelo \& Stenroos, Psoroma melanizum Zalhbr. o Ps. Pholidotoides (Nyl.) Räs., se obtenga un mayor soporte en los estudios moleculares y se compruebe que pertenecen a otro género.

En cuanto a las especies con una Cyanobacteria como fotobionte primario, estas presentan un patrón de distribución muy distinto. A nivel mundial, se extienden en ambos hemisferios y tanto en zonas templado cálidas como en zonas templado frías (Jørgensen, 1994). De las 4 especies con Nostoc encontradas en la Argentina, 3 de ellas (P. conoplea, P. malmei y P. tavaresii), fueron encontradas también en distintos países a lo largo de la cordillera de los Andes (Jørgensen \& Arvidson, 2004; Jørgensen \& Sipman, 2004). Es difícil, sin embargo, establecer un patrón de distribución de este elemento con tan pocos registros. A su vez, $P$. hookeri, es una especie con una clara distribución bipolar (Jørgensen, 1978).

\section{Contribución DE LOS AUtORES}

Todos los autores contribuyeron en la realización del presente trabajo, tanto en la realización de las tareas de campo y laboratorio, como en la preparación del manuscrito.

\section{Agradecimientos}

Los autores agradecen a los curadores de los herbarios por el préstamo de colecciones. (BA, BM, LIL, MSC, H, S, UPS). La presente investigación fue financiada por la Universidad Nacional del Comahue (Proyecto B207) y la Agencia Nacional de Promoción Científica y Tecnológica (PICT 0669-2016).

\section{Bibliografía}

BARRENO, E. \& S. PEREZ-ORTEGA. 2003. Líquenes de la reserva natural integral de Muniellos, Asturias. KRK Ediciones, Oviedo.

CALVELO, S. 1992. Novedades para la flora liquénica del Parque Nacional Nahuel Huapi y sus alrededores (Argentina). Bol. Soc. Argent. Bot. 28: 47-54.

CALVELO, S. \& C. ESTRABOU. 1997. The genus Cetrariastrum in southern South America and $C$. billingsii as a taxonomic synonym of $C$. americanum. Lichens 1: 11-17.

CALVELO, S. \& S. LIBERATORE. 2002. Catálogo de los Líquenes de la Argentina. Kurtziana 29: 7-170.

EKMAN, S., M. WEDIN, L. LINDBLOM \& P. M. JØRGENSEN. 2014. Extended phylogeny and a revised generic classification of the Pannariaceae (Peltigerales, Ascomycotina). Lichenologist 46: 627656. https://doi.org/10.1017/S002428291400019X

ELIX, J. A., U. ENGKANINAN, J. A. JONES, C. L. RASTON, M. V. SARGENT \& A. H. WHITE. 1978. Chemistry and crystal structure of Leprolomin, a novel diphenyl ether from the lichen Psoroma leprolomum. Aust. J. Chem. 31: 2057-2068.

ELIX, J. A., L. LAJIDE \& D. J. GALLOWAY. 1982. Metabolites from the lichen genus Psoroma. Aust. J. Chem. 35: 2325-2333. https://doi.org/10.1071/CH9822325 
ELVEBAKK, A. 2013. Pannaria minutiphylla and P. pulverulacea, two new and common, austral species, previously interpreted as Pannaria microphyllizans (Nyl.) P. M. Jørg. Lichenologist 45: 9-20. https://doi.org/10.1017/S0024282912000679

ELVEBAKK, A. \& D. J. GALLOWAY. 2003. Notes on the heterogeneous genus Psoroma s. lat. Austr. Lich. 53: 4-9.

ELVEBAKK A, J. W. BJERKE. 2005. Pannaria isabellina (Vain.) comb. nov., a remarkable lichen species from Chile. Lichenologist 37: 47-54. https://doi.org/10.1017/S0024282904014525

ELVEBAKK, A., J. FRITT-RASMUSSEN \& J. A. ELIX. 2007. The New Zealand lichen Pannaria leproloma (Nyl.) P. M. Jørg. and its panaustral relative $P$. farinosa nom. nov. Lichenologist 39: 349-359. https://doi.org/10.1017/S0024282907006913

ELVEBAKK, A., E. H., ROBERTSEN, C. H. PARK \& S. G. HONG. 2010. Psorophorus and Xanthopsoroma, two new genera for yellow-green, corticolous and squamulose lichen species, previously in Psoroma. Lichenologist 42: 563-585. https://doi.org/10.1017/S0024282910000083

FRYDAY, A. M., A. ORANGE, T. AHTI, D. O. ØVSTEDAL \& D. E. CRABTREE, 2020. An annotated checklist of lichen-forming and lichenicolous fungi reported from the Falkland Islands (Islas Malvinas). Glalia 8:1.

GALLOWAY, D. J. 1985. Flora of New Zealand: Lichens. Hasselberg, New Zealand Government Printer, Wellington.

GALLOWAY, D. J. 2007. Flora of New Zealand: Lichens. Rev. 2nd ed. Manaaki Whenua Press, Lincoln.

GALLOWAY, D.J. 2008. Godley review, Austral Lichenology: 1690-2008. New Zeal. J. Bot. 46: 433521. https://doi.org/10.1080/00288250809509781

GALLOWAY, D.J. \& W. QUILHOT. 1998. Checklist of Chilean lichens. Gay. Bot. 55: 155-156.

GAllowAY, D.J., W. QUILHOT \& P. M. JØRGENSEN. 2006. Pannaria conoplea and $P$. tavaresii (Ascomycota: Pannariaceae) new to Chile. Lichenologist 38: 83-87. https://doi.org/10.1017/S0024282905001350

HOLMGREN, P.K. \& N. H. HOLMGREN. 2001. Index Herbariorum: Part 1. 8th ed., New York Botanical Garden, New York.

HOOKER, J. D. \& T. TAYLOR. 1844. Lichenes antarctici. Lond. J. Bot. 3: 634-658.

JØRGENSEN, P.M. 1978. The lichen familiy Pannariaceae in Europa. Op. Bot. 45: 1-124.
JØRGENSEN, P.M. 1994. Studies in the lichen family Pannariaceae VI: The taxonomy and phytogeography of Pannaria Del. s. lat. J. Hatt. Bot. Lab. 76: 197206.

JØRGENSEN, P.M. 2000a. Studies in the lichen family Pannariaceae IX: A revision of Pannaria subg. Chryopannaria. Nova Hedwigia 71: 405-414.

JØRGENSEN, P.M. 2000b. Survey of the lichen family Pannariaceae on the American Continent, North of Mexico. Bryologist 103: 670-704. https://doi. org/10.1639/0007-2745(2000)103[0670:SOTLFP] 2.0.CO;2

JØRGENSEN, P.M. 2001. New species and records of the lichen family Pannariaceae from Australia. Bibliotheca Lichenologica 78: 109-139.

JØRGENSEN, P. M. 2002. Conspectus familiae Pannariaceae (Ascomycetes lichenosae). Ilicifolia 4: $1-78$.

JØRGENSEN, P. M. 2007. Pannariaceae. In: AHTI, T., P.M. JØRGENSEN, H. KRISTINSSON, R. MOBERG, U. SØCHTING \& G. THOR (eds.), Nordic Lichen Flora vol. 3: Cyanolichens, pp. 96112. The Nordic Lichen Society, Uddevalla.

JØRGENSEN, P. M. \& GALLOWAY, D.J. 1992. Pannariaceae. Flora of Australia 54: 246-293.

JØRGENSEN, P. M. \& L. ADVIDSSON. 2004. The lichen family Pannariaceae in Ecuador. Symb. Bot. Ups. 34: 113-132.

JØRGENSEN, P.M. \& H. J. M. SIPMAN. 2004. A revision of Pannaria rubiginosa complex in South America. Nova Hedwigia 78: 311-327. https://doi.org/10.1127/0029-5035/2004/0078-0311

KANTVILAS, G. \& GUEIDAN, C. 2018. Pannaria hookeri (lichenised Ascomycetes) - a remarkable new record for Australia. Muelleria 36: 74-80.

LAMB, I.M. 1958. La vegetación liquénica de los Parques Nacionales Patagónicos. An. Parq. Nac. 7: $1-188$.

MALME, G.O. 1926. Die Pannariazeen des Regnellschen herbars. Ark. Bot. 20: 1-17.

MÜLLER ARGOVIENSIS, J. 1888. Lichens. In: HARRIOT, P., P. PETIT, J. MÜLLER ARGOVIENSIS, E. BESCHERELLE, C. MASSALONGO \& A. FRANCHET (eds.). Mission Scientifique du Cap Horn (1882-1883), tome V: botanique, pp. 141-172. Gauthier-Villars et fils, Paris.

ORANGE, A., P.W. JAMES \& F.J. WHITE. 2010. Microchemical methods for the identification of lichens. 2nd ed. British Lichen Society, London. 


\section{A. Passo et al. - El género Pannaria en la Argentina}

ØVSTEDAL, D.O. \& R. I. LEWIS-SMITH. 2001. Lichens of Antarctica and South Georgia: A Guide to Their Identification and Ecology. Cambridge University Press, Cambridge.

PASSO, A., S. CALVELO \& E. STOCKERWÖRGÖTTER. 2004. Taxonomic notes on Pannaria pallida from Southern South America and New Zealand. Mycotaxon 90: 55-65.

PASSO, A. \& S. CALVELO. 2006. New reports and combinations in the family Pannariaceae (Lecanorales, lichenized Ascomycota). Lichenologist 38: 549-555. https://doi.org/10.1017/S0024282906005688

PASSO, A. \& S. CALVELO. 2011. Pannaria byssoidea (Pannariaceae), a new squamulose species from southern South America. Bryologist 114: 756-763. https://doi.org/10.1639/0007-2745-114.4.756

PASSO, A., S. STENROOS \& S. CALVELO. 2008. Joergensenia, a new genus to accommodate
Psoroma cephalodinum (Lecanorales, lichenized Ascomycota). Mycol. Res. 112: 1465-1471.

https://doi.org/10.1016/j.mycres.2008.06.025

WEDIN, M., P.M. JØRGENSEN \& S. EKMAN. 2011. Vahliellaceae, a new family of cyanobacterial lichens (Peltigerales, Ascomycetes). Lichenologist 43: 67$72 \mathrm{https}: / /$ doi.org/10.1017/S0024282910000642

WIRTZ, N., C. PRINTZEN \& T. LUMBSCH. 2012. Using haplotype networks, estimation of gene flow and phenotypic characters to understand species delimitation in fungi of a predominantly Antarctic Usnea group (Ascomycota, Parmeliaceae). Org. Div. and Evol. 12: 17-37. https://doi.org/10.1007/s13127-011-0066-y

ZALHBRUCKNER, A. 1917. Schewedischen Expedition nach Patagonien und dem Feuerlande 1907-1909, IV Die Flechten. Kungl. Svensk. Vetensk. Handl. Band 57: 13-15. 
